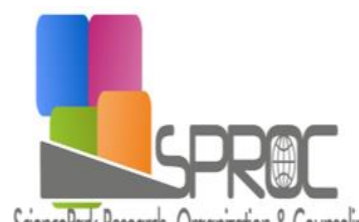

Sceencerour Receerch, Orgonization \& Counseling

g ffh fffh ffh

\section{N'New Trends and Issues Proceedings on Humanities and Social Sciences}

www.prosoc.eu

\title{
g $\mathbf{g}$
}


S

g 
g

Content of Training Program:

g g

g g

fth

g $\quad$ g 


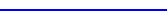

ffh 

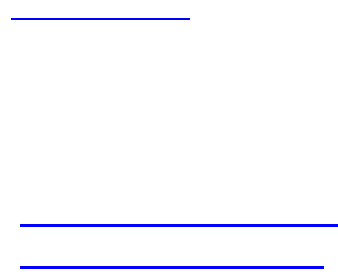